\title{
A RARE CASE OF SUBCUTANEOUS ENTOMOPHTHOROMYCOSIS IN A 11 YEARS OLD CHILD MIMICKING SOFT TISSUE TUMOR TREATED WITH ITRACONAZOLE: CASE REPORT
}

\author{
P. Ravi Kumar Reddy1, Diwakar Gaddi², Ulhas Paga3 ${ }^{3}$ Varun Kumar ${ }^{4}$
}

\section{HOW TO CITE THIS ARTICLE:}

P. Ravi Kumar Reddy, Diwakar Gaddi, Ulhas Paga, Varun Kumar. "A Rare Case of Subcutaneous Entomophthoromycosis in a 11 Years Old Child Mimicking Soft Tissue Tumor Treated with Itraconazole: Case Report". Journal of Evolution of Medical and Dental Sciences 2015; Vol. 4, Issue 15, February 19;

Page: 2626-2629, DOI: 10.14260/jemds/2015/378

\begin{abstract}
Entomophthoromycosis (Subcutaneous zygomycosis) is a subcutaneous fungal infection that is mostly restricted to tropical areas of Asia, Africa, South America characterized by formation of firm, non-tender swellings, generally on the extremities, trunk. This fungal infection presentation may mimic soft tissue tumor in its presentation and there is a need to keep in mind this diagnosis in endemic areas so that early recognition can be done and disfigurement resulting from the advanced disease can be prevented. The disease occurs in age group of 20-60 years but rarely reported in children below 15 years. We present a 11 year old child who presented with multiple subcutaneous nodules in left forearm whose histopathology was showing features of entomophthoromycosis and successfully treated with itraconazole.
\end{abstract}

KEYWORDS: Entomophthoromycosis (subcutaneous zygomycosis), Itraconazole.

INTRODUCTION: Entomophthoromycosis is a rare entity caused by fungal infection. It occurs in two clinical forms, subcutaneous zygomycosis caused by Basidiobolus ranarum and rhinofacial zygomycosis caused by Conidiobolus coronatus. ${ }^{1}$ The infection involves subcutaneous tissue affecting immunocompetent individuals. ${ }^{1}$ The disease occurs in age group of 20-60 years but rarely reported in children below 15 years of age. ${ }^{2}$ We present a 11 year old child who presented with multiple subcutaneous nodules in left forearm whose histopathology was showing features of entomophthoromycosis and successfully treated with itraconazole.

CASE REPORT: A 11-year-old previously healthy boy was admitted with complaints of multiple gradually increasing painless swellings over the left forearm and hand since 6 months with a significant past history of excision of a soft tissue swelling 6 months back details of the procedure done and histopathology not available.

Local examination showed multiple nontender indurated subcutaneous swellings $1-2 \mathrm{~cm}$ size concentrated over dorsal surface of left forearm and left hand with incision scar over ventral aspect. The swellings were firm in consistency and clinical diagnosis of soft tissue tumor recurrence was made. $2 \times 1 \mathrm{~cm}$ epitrochlear lymph node is palpable. 


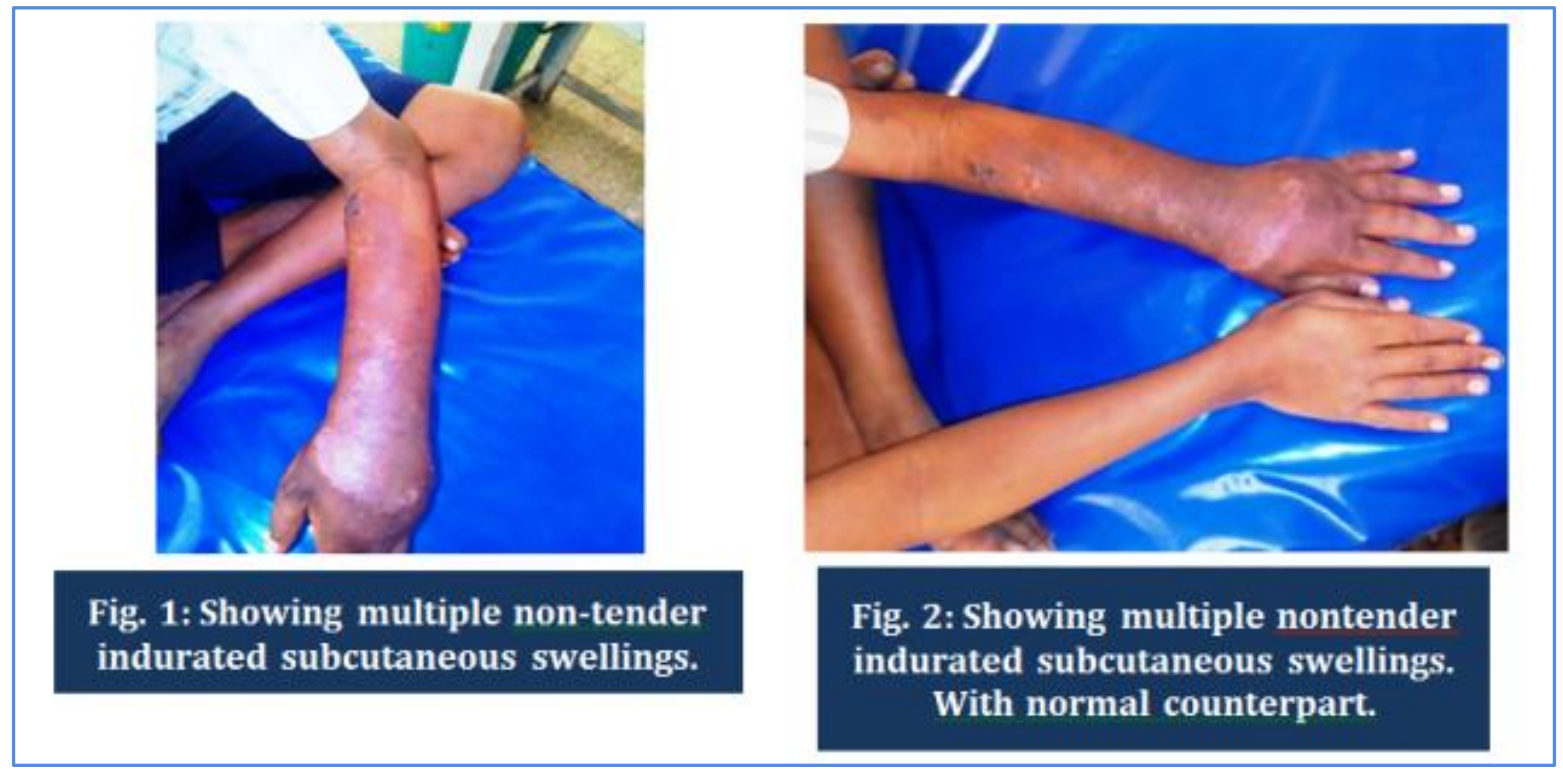

Routine laboratory investigations revealed total count of $12,200 / \mathrm{cmm}$. Hiv status was negative.

Excision biopsy of the epitrochlear lymph node done and incisional biopsy of one of the forearm lesion done. Histopathology of the incisional biopsy showed dense mixed inflammation rich in eosinophils and foreign body giant cell reaction seen around fungal elements that are very broad based, pauciseptate with paucibranching and show Splendore - Hoeppli reaction. Lymph node histopathology showed reactive follicular hyperplasia. Sections are negative for malignancy.

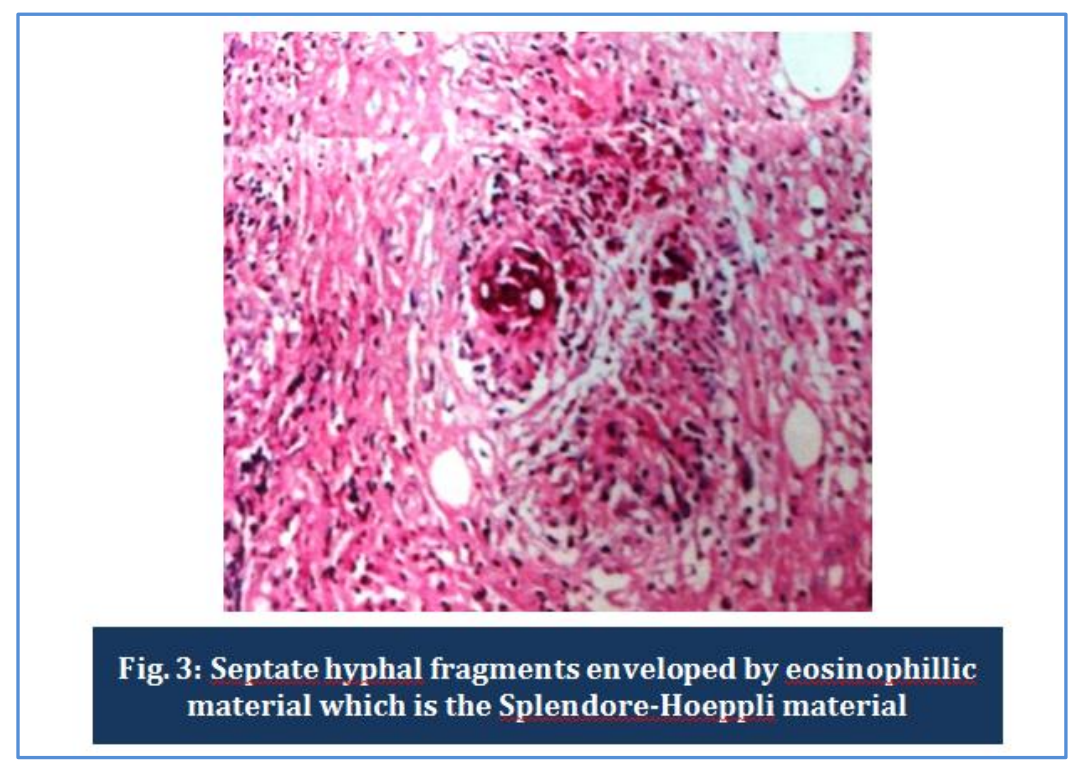

The patient was started on antifungal treatment with tablet itraconazole 100mg per day. And patient was followed up after 15 days which showed decrease in the size of lesions and limb swelling also decreased. Patient continued on itraconazole for 6 months. Complete recovery noted. 


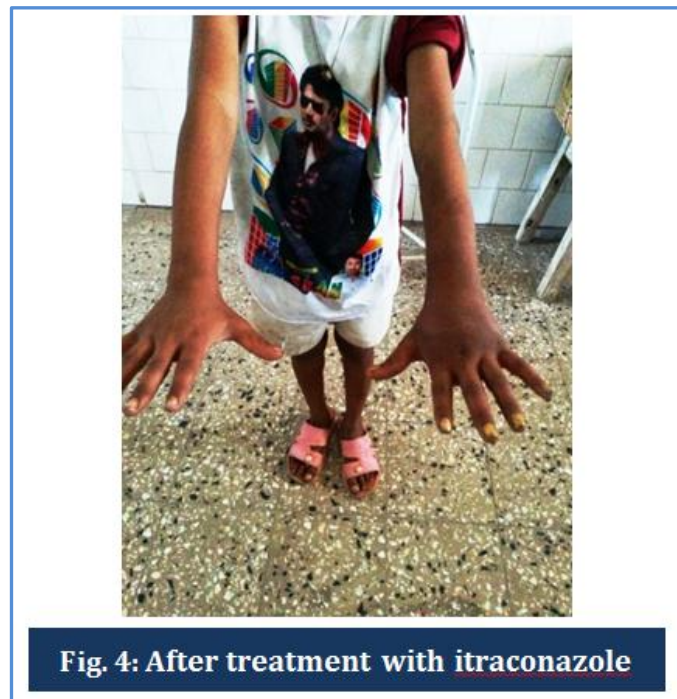

DISCUSSION: Lei-Kian Joe described the first case of entomophthoromycosis in humans in 1956 in Indonesia whose infective agent was Basidiobolus ranarum. ${ }^{3}$ There are approximately 250 cases caused by Basidiobolus have been reported. ${ }^{3}$ Zygomycosis is a class of fungi which causes infections of respiratory tract and subcutaneous tissues. ${ }^{2}$ This class contains teo orders of organisms that cause disease in humans, i.e., Mucorale and Entomophthorale. ${ }^{4}$ Entomophthoromycosis cases have been reported from tropical countries like Nigeria, Ghana, India, Sudan, Uganda and Indonesia. ${ }^{5}$ The infection usually occurs as small papules following a scratch or puncture by an insect, plant, or fungus-bearing object. ${ }^{6}$ Possibly due to the production of protease enzyme by the fungus, it is able to invade subcutaneous tissues and often mimick soft tissue tumor. ${ }^{7}$ The disease primarily involves subcutaneous tissue, but occasionally deeper structures are invaded. ${ }^{3}$

Entomophthoromycosis is a curable condition which can mimick a neoplasm like soft tissue tumor, synovial sarcoma, and Burkitt's lymphoma. ${ }^{8}$ The disease occurs in age group of 20-60 years but rarely reported in children below 15 years of age. ${ }^{2}$

Histologically, entomophthoromycosis is associated with eosinophillic infiltration due to Th1 and Th2 immune response which causes release of IL-4 and IL-10. ${ }^{9}$ The other important feature the "Splendore-Hoeppli" reaction characterized by presence of broad thin walled infrequently septate hyphal fragments enveloped by eosinophillic material which is the Splendore-Hoeppli material. ${ }^{1}$

Patients with this fungal infection respond well with oral potassium iodide as well as azoles especially itraconazole. ${ }^{10}$

Thus to summarize, entomophthoromycosis presents as subcutaneous swellings, painless, and usually observed in tropical areas which often mimicks soft tissue tumor. High index of suspicion in endemic areas and demonstration of aseptate fungal hyphae on histopathology clinches the diagnosis. Fungus is difficult to grow on culture. Treatment is with potassium iodide and itraconazole.

CONCLUSION: Entomophthoromycosis should be in the differential diagnosis of subcutaneous swellings in tropical areas because the condition is potentially curable. Treatment should be started based on the histopathology report with potassium iodide and azoles especially itraconazole. 


\section{REFERENCES:}

1. F. W. Chandler and J. C. Watts, "Fungal Diseases," in Anderson's Pathology, I. Damjanov and J. Linder, Eds., Mosby, St. Louis, Mo, USA, 10th edition, 1996.

2. S.K. Kabra, Y. Jain, T. Sudhin, K.V. Iyer, Sunil A. Ninan, V. Seth. Successful Treatment of Entomophthoromycosis with Itraconazole. Indian Pediatrics Volume 35-february 1998.

3. Dr. Jyothi k. Kudrimoti, Dr. Savita S. Patil, Dr. Somnath S Khedkar, Dr. Medha M. Khandekar, Dr. Shaila C. Puranik. Subcutaneous Entomophthoromycosis mimicking soft tissue tumour: Report of two cases in Maharashtra, India. Paripex - Indian Journal of Research, Volume: 3 | Issue: 2 | Feb 2014.

4. Mortez ML, Grist WJ, Sewell CW. Zygomycosis presenting as nasal polyp in a healthy child. Arch Otolaryngol Head Neck Surg 1987; 113: 550-552.

5. Williams AO. Pathology of Phycomycosis due to species Entomophthora and Basidiobolus species. Arch Path 1969; 87: 13-20.

6. Leonora Maciel de Souza Vianna, Marcus Vinícius Guimarães de Lacerda and Mário Augusto Pinto de Moraes. Case report of subcutaneous entomophthoromycosis with retroperitoneal invasion. Revista da Sociedade Brasileira de Medicina Tropical 38(4): 348-350, jul-ago, 2005.

7. Okafor JI. Purification and characterization of protease enzymes of Basidiobolus and Conidiobolus species. Mycoses 37: 265-269, 1994.

8. Z. U. Khan, M. Khoursheed, R. Makar, et al., "Basidiobolus ranarum as an etiological agent of gastrointestinal zygomycosis," Journal of Clinical Microbiology, vol. 39, no. 6, pp. 2360-2363, 2001.

9. S. Rane, A. Jayaraman, S. Puranik, S. Deshmukh, and V. Bapat, "Entomopthoromycosis-Report of four cases," Indian Journal of Dermatology, Venereology and Leprology, vol. 68, no. 5, pp. 296297, 2002.

10. S. Sujatha, C. Sheeladevi, A. B. Khyriem, S. C. Parija, and D. M. Thappa, "Subcutaneous zygomycosis caused by Basidiobolus ranarum-a case report," Indian Journal of Medical Microbiology, vol. 21, no. 3, pp. 205-206, 2003.

\section{AUTHORS:}

1. P. Ravi Kumar Reddy

2. Diwakar Gaddi

3. Ulhas Paga

4. Varun Kumar

\section{PARTICULARS OF CONTRIBUTORS:}

1. Assistant Professor, Department of Surgery, VIMS, Bellary.

2. Professor, Department of Paediatric Surgery, VIMS, Bellary.

3. Post Graduate, Department of Paediatrics, VIMS, Bellary.

FINANCIAL OR OTHER COMPETING INTERESTS: None
4. Post Graduate, Department of Surgery, VIMS, Bellary.

\section{NAME ADDRESS EMAIL ID OF THE CORRESPONDING AUTHOR:}

Dr. P. Ravi Kumar Reddy,

C/o Shekappa C. M,

B/24, Staff Quarters, VIMS,

Cantonment, Bellary.

E-mail: doc_shekar@yahoo.com

Date of Submission: 15/02/2015.

Date of Peer Review: 16/02/2015.

Date of Acceptance: 17/02/2015.

Date of Publishing: 19/02/2015. 